\title{
Young people, \\ transition into work and mental wellbeing
}

A summary report prepared for the Victorian Health Promotion Foundation

Dr Humaira Maheen

Associate Professor Allison Milner

Centre for Health Equity

School of Population and Global Health

The University of Melbourne
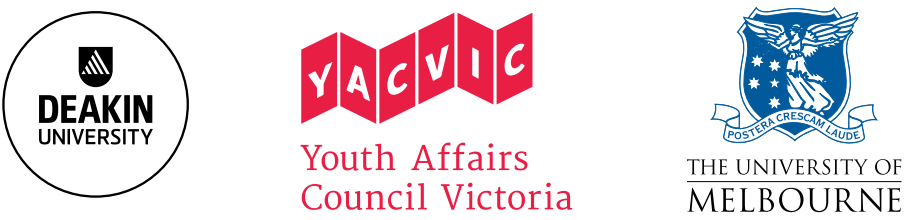


\section{Contents}

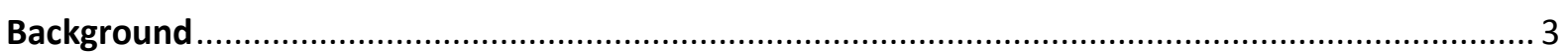

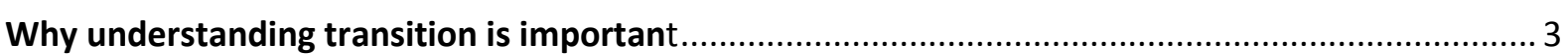

Life course and employment experiences of young people .................................................. 4

1. Employment experiences as high-school students.................................................. 4

2. Employment experiences as higher education students (University and TAFE) .................6

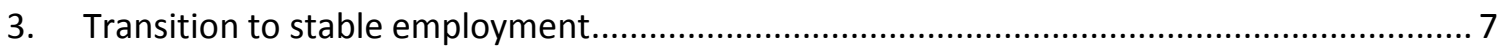

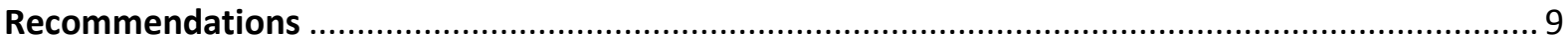

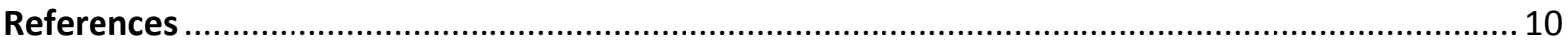

We honour the memory of the inimitable Associate Professor Allison Milner who had a passion for building evidence to improve the mental health of young people. 


\section{Background}

Young people (aged 12-25 years) are recognised as priority group in the Victorian Health Promotion Foundation's (VicHealth) Mental Wellbeing Strategy 2019-2023. Evidence indicates that youth (12-17 years) and young adulthood (18-25 years) are characterised by a series of critical transitions during which mental wellbeing can be compromised. The transition from education to work is one such example. Since 2015 VicHealth has supported three related studies that seek to understand and support the mental health of young people, going through this transition. This report summarises the findings of these studies. Recommendations for how employment and transition into employment can be optimised to improve the mental health of young people are provided at the end of the report.

The first empirical study used a longitudinal dataset to understand how job stressors (defined as high job demand, poor job control, job strain and job insecurity) contribute to mental health problems for young Australians. The study was followed by a systematic review of previous research on the effects of transition into employment and early working experiences on the mental health of young people. The third study was a qualitative study, where we interviewed young Australians about their lived experiences of transitioning from education to work.

The objectives of the studies were:

Study one: To conduct a longitudinal assessment of the relationship between job stressors and mental health in young Australians.

Study two: To systematically review the evidence on the effects of transition into employment and early working experiences on the mental health of young people.

Study three: To explore young people's lived experiences of transitioning from education to work, and the impact of this on their mental health.

\section{Why understanding transition is important}

Adolescents (12-17 years) and young adults (18-25 years) experience considerable life changes within a short period of time. These changes include the transition between school and work, the formation of new relationships and moving away from family. Obtaining a job is a critical step towards independence and self-sufficiency. In Australia, a number of young people begin some form of paid employment while they are still in school, while a greater number of young Australians choose to work after secondary school either concurrently or independently of higher degree study. 
The research outlined in this report identifies early working life (inclusive of the period of transition from education into paid employment) as being a time of particular vulnerability for young people. Our work shows that it is critically important that we get this period "right" for young people, as high-quality employment experiences will translate into sustainable, happier and more productive working lives. The penalty for failing to address this critical social determinant of health is a greater likelihood of young people falling into unemployment and becoming "NEET" (not in education, employment or training). Not to mention, there is accumulating evidence of a scarring effect of unemployment on mental health, which is particularly apparent for young workers (1). This is significant given that young people in Australia are the most likely to be without a job and form the largest group of job-seekers. This problem is more pronounced in regional and remote areas of the country, where these issues are compounded by a poor supply of jobs.

\section{Life course and employment experiences of young people}

To understand how young people experience work we have made a distinction between three specific life-stages: 1) work experiences as high school students; 2 ) work experiences as higher education students (University, other training Technical and Further Education (TAFE)), and; 3) transitioning into stable employment. We define stable employment as paid work (full-time, ongoing, permanent, including part-time) where a young person reports being satisfied with conditions and hours. It is also possible to consider aspects of career aspirations. However, in addition to this, stable employment could be also considered as work that satisfies a young person's expectations and aspirations regarding their career ambitions and needs, at that point in their life.

\section{Employment experiences as high-school students}

Our qualitative interviews (study three) showed that businesses in metropolitan areas were happy to employ local young people. However, these young people often found it difficult to juggle work and education. Flexibility from employers during exam times made dealing with these competing demands easier. Young people reported quite a different experience of employment in regional areas where the availability of jobs was a big concern. Young people reported that local businesses did not have many opportunities for them. This lack of early experience appears to have flow on effects, in that a lack of previous work experience hindered their ability to find stable and sustainable work.

Results of our systematic review (study two) found that work-related stressors experienced during adolescence resulted in a decrease in self-esteem, lower self-efficacy, and an increase in depression. 
Findings from study two also suggested that individual coping strategies characterised by passivity were associated with increased problems in obtaining employment among young people. In contrast, individuals who displayed adaptive achievement strategies (including realistic expectations of success and adaptive coping) had greater likelihood of obtaining employment (2). Our qualitative study (study three) provided a good example of this type of adaptive coping. In this case, a participant described a difficult first employment experience characterised by bullying and discrimination. This experience led them to learn more about their work rights, which lead to a greater ability to negotiate with their employers about employment conditions.

During interview, I said to her [employer] that I was only applying for this job because I want job security - I made that so clear. I was like I'm a student, I have bills to pay and all that sort of thing. I don't want to keep jumping between jobs and end up being promised ten hours a week and then getting three. I made that really clear, I was like: I want at least 15 hours just to survive.

The review findings also showed the importance of having a realistic career plan. In our qualitative study, a young person applied for a relatively senior role in an organisation. The employer explained how they did not fit the criteria but offered them an entry level position which matched the young person's skillset. That person stated that they were satisfied with the work and could see it was a useful steppingstone. This shows the importance of career planning, applying for the right jobs, and getting adequate feedback from employers.

So the [employer] gave me the feedback that they preferred someone who had a university degree and [...] they said, I know you're not meant to discriminate on your age but you're a bit too young for what we're looking for [...] and they said to me there are a couple of internal openings we have at the moment and would you like to be considered for any of them? And I was, like, yes, yes, of course and I got there eventually.

Our results suggest that high school could be an important opportunity to implement programs for young job seekers. There is substantial literature (including Australian literature) which emphasises the importance of high school interventions for young people seeking employment, transitioning into the workforce, and having realistic career plans (3-7). For example, the 'Real Game Series program' in Victoria demonstrates the use of gaming technology to engage students in 'big questions' regarding their future through role-play and scenarios (3). Another good example is the NSW 'School to Work Program' which actively supports students' informed, planned and quality transition through school and from school (4). The program focuses on four key dimensions of career planning 1) planning transition pathways 2) exploring career futures 3) strengthening student 
outcomes through vocational learning and 4) building networks and connections. The evaluation of both the Real Game Series and School to Work Program show promising results to increase students' understanding of the world of work, and what it means to be engaged in the labour force.

\section{Employment experiences as higher education students (University and TAFE)}

There is now substantial evidence that job stressors can have a detrimental impact on the mental health of higher education students. Our review findings show that high job demands and time pressure can lead to anxiety, depression, and social dysfunction in students $(8,9)$. These findings were echoed in the qualitative study by students who were working in stressful environments. Participants reported that managing studies and work simultaneously was difficult.

So, with their university schedule I mean it's a lot, with the study hours it's a lot. Some students don't get their lectures recorded. Getting to the city is going to take longer for them or the distance to their workplace is going to be twice as long. Maybe they live further away, maybe they live right in the city. (difficult experience)

On the contrary, those who worked in a more supportive environment did not feel the same pressures.

I think, everyone who's worked in hospitality's got a story where they cried, which I think is so true and that's not necessarily a fault of the employer. I've been there (in that job) for four years now, and they've respected me as a reliable employee enough that when I require something, they're very like good about it. They've given me regular shift with sufficient hours that suit my needs and study schedule. (good experience)

The systematic review also highlights the impact of temporary work on increased depressive symptoms (10), while job insecurity was found to be related to diminished life satisfaction (11). These problems were noted in the qualitative study, where job insecurity and the casual nature of work were raised as major concerns by all employed participants. Young people were more likely to be employed in part-time or casual work, which in theory should have provided them with the flexibility needed to support their academic work. However, young people (>20 years, currently studying) found that casual work or being on a short contract was a constant worry which affected their overall feelings of security in life and ability to maintain housing. Participants also found it hard to find jobs that accommodated their study commitments. Many had neither guaranteed ongoing shifts or time off work allowed for study. 
I recently went back to XYZ employer [...] my [other] contract ends in August and I am like I don't have a secure job after this [...] and I feel like everything is getting out of control. I need to pay for things that I have and it's like going back to XYZ and realising how messy it is, and especially after having this experience [of working in a good environment] then going back to a place like XYZ is just awful.

These findings align with the results of the review, which suggested that students who were not satisfied with their jobs were more likely to experience low self-esteem, depressive affect, and minor psychiatric morbidity, compared with students who were satisfied with their jobs (12). The qualitative study also demonstrated that students who engaged in internships, placement programs, or relevant work experience during education found transitioning into employment relatively easier than those without similar experience. So, while this group may experience temporary hardships in balancing work and study, these experiences were reported to be beneficial in the long run.

\section{Transition to stable employment}

Before transitioning to stable employment (see page 3 for definition), young people who are unemployed (for long time) or who work in temporary or casual jobs are at increased risk of poor mental health. The findings from HILDA analysis (study one) suggests a small but statistically significant drop in life satisfaction when people entered most types of employment arrangement and statuses compared to when they were not in labour force (NILF). There were similar declines in life satisfaction (approx. a decline of 0.05 of a point) for all types of employment contracts (permanent, casual or labour hire and fixed term). This could perhaps be because of the unstable employment conditions that many young Australians experienced during the transition phase. The review findings suggested that unemployment (and the accumulation of unemployment) was linked with deteriorating mental health (measured through three items capturing depressive and nervous symptoms, and sleeping problems) among young people (13). Males employed casually or on fixed-term contracts reported higher odds of suicidal ideation (14), suggesting the damaging effect of 'precarious employment'. However, one study found no association between precarious employment and mental health, as measured using the SF-12) (15). This suggests that there may be differential effects depending on the mental health outcome under study.

Findings from study two suggest among those who were employed, self-reported and global 'job stress' was linked with poor mental health such as symptoms of common mental disorders (16-18) and low life satisfaction (16). There was also some evidence about the negative impacts of mental health on specific psychosocial job stressors. 
These included:

- a high workload and long working hours $(8,15,19)$.

- effort-reward imbalance/lack of rewards and job strain $(17,20,21)$.

- Low job control, job insecurity and perceived unfair pay $(10,11,14)$

- Harassment or discrimination (22)

- Bullying or harassment (23).

Across all studies which were included in the review, it is notable that young workers were more likely to be exposed to poor working conditions than older workers. 


\section{Recommendations}

The combined recommendations from three studies are as follows:

\section{School level}

1. Offer more proactive vocational support, such as helping young people in writing CVs and cover letters, reading and selecting job advertisements that match their skillset and criteria, understanding employment contracts, and providing a basic education of employment rights and conditions.

2. Offer an online platform which advertises entry-level jobs, internships and work-placements relevant to young people

\section{Employer level}

1. Promote paid internships, job placement programs, or training opportunities for young people. This will allow them to gain experiences which may be required for entry level positions.

2. Build supervisors' capacities in interpersonal communication and people management skills. Given that most of the young people in temporary jobs are also supervised by somebody who is of similar age (2-3 years older than them), this training could help reduce the incidences of bullying that many young workers experience from their immediate supervisors.

3. Providing a high quality environment and psychosocial support for younger workers will protect and promote their wellbeing and may reduce the likelihood of later mental health problems, particularly as this is likely to set up the young person for a working life characterised by good psychosocial quality jobs.

4. Encouraging employers to enable young workers to have greater control over working hours, where appropriate. Employers could also offer more security and understanding around young people's circumstances such as needing time off for exams, and ensuring young workers feel secure in continuing to have their job. 


\section{References}

1. Daly M, Delaney L. The scarring effect of unemployment throughout adulthood on psychological distress at age 50: Estimates controlling for early adulthood distress and childhood psychological factors. Social Science \& Medicine. 2013;80:19-23.

2. Määttä S, Nurmi J-E, Majava E-M. Young adults' achievement and attributional strategies in the transition from school to work: antecedents and consequences. European Journal of Personality. 2002;16(4):295-311.

3. Victorian State Government Education and Training. The Real Game Series Melbourne, Australia Victorian Government 2017 [Available from:

https://www.education.vic.gov.au/school/teachers/teachingresources/careers/Pages/Expired/realgame.aspx.

4. NSW Government. 2017 Overview- School to Work Program 2017 [Available from: https://schoolsequella.det.nsw.edu.au/file/59efb222-958f-4e42-840b-387f57b93d3a/1/school-to-workreport-overview-2017.pdf.

5. Galliott Ny, Graham LJ. School based experiences as contributors to career decision-making: Findings from a cross-sectional survey of high-school students. The Australian Educational Researcher. 2015;42(2):179-99.

6. Mowbray CR, Collins M, Bybee D. Supported education for individuals with psychiatric disabilities: Longterm outcomesfrom an experimental study. Social Work Research. 1999;23(2):89-100.

7. Ling TJ, O'Brien KM. Connecting the forgotten half: The school-to-work transition of noncollege-bound youth [Occupational Interests \& Guidance 3610]. US: Sage Publications

US; 2013 [4:[347-67]. Available from:

http://ovidsp.ovid.com/ovidweb.cgi?T=JS\&PAGE=reference\&D=psyc10\&NEWS=N\&AN=2013-23384-005.

8. Melchior M, Caspi A, Milne BJ, Danese A, Poulton R, Moffitt TE. Work stress precipitates depression and anxiety in young, working women and men. Psychological Medicine. 2007;37:1119-29.

9. Baldwin PJ, Dodd M, Wrate RW. Young doctors' health-I. How do working conditions affect attitudes, health and performance. Social Science \& Medicine. 1997;45(1):35-40.

10. Quesnel-Vallée A, DeHaney S, Ciampi A. Temporary work and depressive symptoms: A propensity score analysis. Social Science \& Medicine. 2010;70(12):1982-7.

11. Helbling L, Kanji S. Job Insecurity: Differential effects of subjective and objective measures on life satisfaction trajectories of workers aged 27-30 in Germany. Social Indicators Research. 2017:1-18.

12. Winefeld AH, Tiggemann M, Goldney RD. Psychological concomitants of satisfactory employment and unemployment in young people. Social psychiatry and Psychiatric Epidemiology. 1988;23.

13. Strandh $\mathrm{M}$, Winefield $\mathrm{AH}$, Nilsson $\mathrm{K}$, Hammarström A. Unemployment and mental health scarring during the life course. European Journal of Public Health. 2014;24(3):440-5.

14. Milner A, Currier D, LaMontagne AD, Spittal MJ, Pirkis J. Psychosocial job stressors and thoughts about suicide among males: a cross-sectional study from the first wave of the Ten to Men cohort. Public Health. 2017;147:72-6.

15. LaMontagne AD, Keegel T. Reducing Stress in the Workplace: An Evidence Review, Full Report.

Melbourne: Victorian Heath Promotion Foundation (VicHealth); 2012. Contract No.: ISBN: 978-1-921822-08-7.

16. Buddeberg-Fischer B, Klaghofer R, Stamm M, Siegrist J, Buddeberg C. Work stress and reduced health in young physicians: Prospective evidence from Swiss residents. International Archives of Occupational and Environmental Health. 2008;82:31-8.

17. Clark C, Pike C, McManus S, Harris J, Bebbington P, Brugha T, et al. The contribution of work and nonwork stressors to common mental disorders in the 2007 Adult Psychiatric Morbidity Survey. Psychological Medicine. 2012;42:829-42.

18. Martins LCXL, C. S. Military hierarchy, job stress and mental health in peacetime. Occupational Medicine. 2012;62(3):182-7. 
19. Fujino YM, T.; Izumi, H.; Kumashiro, M.; Hasegawa, T.; Yoshimura, T. Job stress and mental health among permanent night workers. Journal of Occupational Health. 2001;43(6):301-6.

20. Wiesner $\mathrm{M}$, Windle $\mathrm{M}$, Freeman $\mathrm{A}$. Work stress, substance use, and depression among young adult workers: An examination of main and moderator effect models. Journal of Occupational Health Psychology. 2005;10(2):83-96.

21. Yoon SL, Kim J-H. Job-related stress, emotional labor, and depressive symptoms among Korean nurses. Journal of Nursing Scholarship. 2013;45(2):169-76.

22. Rospenda KM, Richman JA, Shannon CA. Prevalence and mental health correlates of harassment and discrimination in the workplace. Journal of Interpersonal Violence. 2009;24(5):819-43.

23. Milner A, Page K, Witt K, LaMontagne AD. Psychosocial Working Conditions and Suicide Ideation: Evidence From a Cross-Sectional Survey of Working Australians. Journal of Occupational and Environmental Medicine 2016;58(6):584-7. 


\section{VicHealth}

Victorian Health Promotion Foundation PO Box 154 Carlton South

Victoria 3053 Australia

$T+61396671333 F+61396671375$

vichealth@vichealth.vic.gov.au

vichealth.vic.gov.au

twitter.com/vichealth

facebook.com/vichealth

VicHealth acknowledges the support of the Victorian Government.

(C) VicHealth 2019

October 2019 P-MW-807

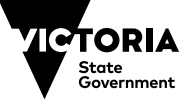

